\title{
Synthesizing Pt-Ni/C Nanoframes electrocatalyst using the solvothermal and in-house developed method for PEM fuel cells
}

\author{
J Negondeni' ${ }^{1}$, T Ngwenya ${ }^{1,2}$ \\ ${ }^{1}$ Mintek, Advanced Materials Division, Malibongwe Drive, Randburg 2194, South Africa \\ ${ }^{2}$ HySA catalysis, South Africa \\ Email:Thelman@mintek.co.za
}

\begin{abstract}
As South Africa moves towards the production and storage of green energy sources, proton exchange membrane (PEM) fuel cells have been characterized as promising energy sources for transportation, heating, and power sources and have an efficient energy conversion that does not allow greenhouse gas emissions. However, to improve the energy efficiency and to reduce the system cost, and make it suitable for large-scale commercialization, precious metal catalyst needs to be developed with improved catalyst activities for PEM fuel cells. Due to the high cost of platinum, platinum alloy nanostructures have been investigated for use as an electrocatalyst in PEM fuel cells. Platinum-nickel alloy nanostructures in previous research studies have shown 36- and 22-times enhancement in mass and specific activity respectively, towards the cathodic oxygen reduction reaction (ORR) in PEM fuel cells and for the methanol oxidation reaction (MOR) in direct methanol fuel cell (DMFC) than the Pt/C catalyst. Therefore, this research focused on developing rich Pt-skin platinumnickel nanoframes which were synthesized using solvothermal and in-house developed methods. The intermediate products were etched to remove the interior using either a weak acid or an oxidative acid for comparison. The final product was supported by Vulcan XC-72 at a loading of $20 \mathrm{wt}$. \% Pt-Ni. The properties of Pt-Ni/C will be characterized and evaluated to determine if the nanoframes are formed. The preliminary results for the X-ray diffraction pattern showed that the structure of Pt-Ni contracted and affected the catalyst properties. The catalytic activities were determined by electrochemical methods using thin-film RDE measurements, the results indicated that Pt-Ni as-synthesized has higher specific activity at $900 \mathrm{mV}$ versus RHE. The specific and mass activity of the oxygen reduction reaction for $\mathrm{Pt}-\mathrm{Ni} / \mathrm{C}$ will be compared to the activities of the current high-performing $\mathrm{Pt} / \mathrm{C}$ catalyst.
\end{abstract}

\section{Introduction}

The catalyst used for proton exchange membrane fuel cell (PEMFC) electrochemical interfaces is based on platinum nanoparticles supported on carbon $(\mathrm{Pt} / \mathrm{C})$. Platinum $(\mathrm{Pt})$ is active for both half-cell reactions namely oxygen reduction reaction (ORR) at the cathode and hydrogen oxidation reduction (HOR) at the anode in PEMFC. ${ }^{1}$ However, the commercial application of $\mathrm{Pt} / \mathrm{C}$ catalyst is still seriously disadvantaged by $\mathrm{Pt}$ metal that is relatively expensive and aggregates under poor operating conditions resulting in a costly catalyst with poor electrocatalytic activity on the cathode and poor stability. ${ }^{2}$ Therefore, electrocatalysts with Pt-rich skin nanostructures, Pt nanostructures with reduced sizes, and Pt alloys have been investigated to reduce Pt dosage while improving the atom utilization and increasing Pt's catalytic activity. ${ }^{3}$ Elements such as $\mathrm{Ni}, \mathrm{Ru}, \mathrm{Co}, \mathrm{Fe}$, and $\mathrm{Cu}$ in previous studies were found to have high ORR activity at the cathode without forming hydrogen peroxide when used as cocatalyst together with $\mathrm{Pt}$ to form a bimetallic catalyst. ${ }^{4-6}$ Amongst the mentioned metals, Ni has acquired a lot of attention because of the high catalytic activity and its resistance to corrosion to form Pt-Ni alloys nanoframes. ${ }^{7}$ Pt content in Pt-Ni could be decreased by converting solid nanostructures into hollow nanostructures with ultrathin walls forming Pt-rich skin nanostructures and controlled surface composition. ${ }^{6}$ The advantage of hollow structures over solid particles is that reactants can interact with 3D interior and exterior surfaces in catalytic reactions, whereas $\mathrm{Pt}$ atoms in solid nanoparticles go unused because they cannot participate in electrocatalytic reactions. ${ }^{89}$ Pt-Ni electrocatalysts with ultrafine nanostructures such as nanowire, octahedron, and nanoframes have shown great improvements in accelerating the sluggish ORR due to excellent morphology, good stability, and great surface area owing to their exclusive orientated sides. ${ }^{10}$ This work aims to synthesize platinum-nickel nanoframes supported on carbon (Pt$\mathrm{Ni} / \mathrm{C})$ particularly for the ORR on PEMFC using solvothermal ${ }^{11}$ and the in-house developed methods. In the synthesis of Pt-Ni nanoframes, an intermediate Pt-Ni product is etched to remove the interior leading to the evolution of Pt-Ni nanoframes. ${ }^{8}$

\section{Materials and method}

\subsection{Materials and apparatus}

The materials used in the solvothermal method were platinum (II) acetylacetonate $98 \%\left(\mathrm{Pt}(\mathrm{acac})_{2}\right)$, nickel acetylacetonate $96 \%$ (Ni(acac) $)_{2}$, polyvinylpyrrolidone (PVP) average mol wt. 40, aniline minimum $99.0 \%$, benzyl alcohol $99.8 \%$, oleylamine technical grade $70 \%$, toluene $99.8 \%$, and cyclohexane were sourced from Sigma Aldrich. Ethanol absolute (99.9 \%) and ethylene diamine tetra-acetic acid AR (EDTA) were sourced from ACE's (Associated Chemical Enterprises). High purity water Millipore ${ }^{\circledR},>18.2 \mathrm{M} \Omega$. $\mathrm{cm} @ 25^{\circ} \mathrm{C}$ (HPW) was used throughout the experiment.

Borosilicate glass in a Teflon-lined autoclave was used as a reactor during the thermal process. 
Ultra-sonicator was used to agitate the mixture and ensure that it was well-mixed. A three-necked flask was used as a reactor and heated using a hot plate stirrer including a magnetic stir bar. A Hettich Rotina 420 desktop centrifuge was used to separate the solids from the solution mixture.

\subsection{Experimental procedure}

\subsubsection{Solvothermal synthesis}

The synthesis of the Pt-Ni alloy catalyst was prepared based on literature studies presented by ${ }^{11}$ where $400 \mathrm{mg}$ of PVP and $25 \mathrm{~mL}$ of benzyl alcohol were mixed in a borosilicate glass reactor and sonicated for $10 \mathrm{~min}$. The following reagents, $70 \mathrm{mg}$ of $\mathrm{Pt}(\mathrm{acac})_{2}$, $7 \mu \mathrm{L}$ of aniline, and $60 \mathrm{mg}$ of $\mathrm{Ni}(\mathrm{acac})_{2}$ were added into the sonicated transparent mixture and sonicated for $10 \mathrm{~min}$. The homogenous mixture in borosilicate glass was transferred into a Teflon-lined autoclave and heated at $170{ }^{\circ} \mathrm{C}$ overnight. The autoclave was then cooled down to room temperature with cold water. The resulting Pt-Ni alloy was washed three times with an ethanol and acetone mixture at a volume ratio of $1: 1$ and separated in a centrifuge at a speed of 3,600 RPM. The resultant alloy was dispersed into a mixture of $45 \mathrm{~mL}$ ethanol and $15 \mathrm{~mL}$ of oleylamine in a threenecked flask. The mixture was heated at a temperature of $200{ }^{\circ} \mathrm{C}$ for $5 \mathrm{~h}$ under nitrogen and vigorous stirring. The oleylamine capped Pt-Ni alloy was washed three times with an ethanol and toluene mixture at a volume ratio of $1: 1$ and separated by a centrifuge at a speed of 3,500 RPM. The alloy was then dispersed into $15 \mathrm{~mL}$ of toluene in a vial to which $21 \mu \mathrm{L}$ of oleylamine were added to form an upper oil phase and the bottom aqueous mixture was prepared using $80 \mathrm{mg}$ of EDTA and $10 \mathrm{~mL}$ of HPW. The resultant mixture was transferred into the Teflon-lined autoclave. The autoclave was sealed tight with no leakage and kept at $110{ }^{\circ} \mathrm{C}$ overnight. The resultant Pt-Ni was washed in a centrifuge with an ethanol and cyclohexane mixture at a volume ratio of 1:1. The nanocages were then dispersed into $20 \mathrm{~mL}$ of ethanol for aging and stored for characterization. The Pt-Ni alloy that was dispersed in $20 \mathrm{~mL}$ of ethanol was collected in a centrifuge.

\subsubsection{In-house developed synthesis}

The desired Pt and Ni precursors were mixed in a known volume of benzyl alcohol and sonicated for $20 \mathrm{~min}$. This mixture was added to a reductant at $160^{\circ} \mathrm{C}$ in a three-necked flask. Under a controlled heating rate and inert gas environment, the mixture changed to black. The reaction was stopped by cooling to room temperature. The resulting Pt-Ni intermediate was washed with organic solvents and collected via centrifuge. The intermediate products were etched to remove the interior using acetic acid and nitric acid.

\subsubsection{Etching}

Acetic and nitric acid corrosion methods were used to prepare the process of etching the synthesized Pt-Ni to Pt-Ni nanoframes reported by. ${ }^{8}$

Acetic acid (HOAc) corrosion:

$2 \mathrm{~mL}$ of toluene was mixed with the resulting as-synthesized Pt$\mathrm{Ni}$ and it was sonicated for $5 \mathrm{~min}$. The solution was mixed with 5 $\mathrm{mL}$ of acetic acid and was heated in a hot plate for $2 \mathrm{~h}$ at $90{ }^{\circ} \mathrm{C}$.
The resulting product was washed twice with an ethanol/hexane mixture. The sample was collected by centrifuge at 3,500 RPM

Nitric Acid $\left(\mathrm{HNO}_{3}\right)$ corrosion:

The as-synthesized Pt-Ni was mixed with $2 \mathrm{M}$ of nitric acid and it was sonicated for $5 \mathrm{~min}$. The mixture was then heated in the hot plate for $12 \mathrm{~h}$ at $70{ }^{\circ} \mathrm{C}$. The final product was washed three times with absolute ethanol and then washed once with an ethanol/ hexane solution. The sample was collected using centrifugation at a speed of 3,500 RPM.

\subsubsection{Loading onto the supporting carbon}

The loading of carbon was based on literature studies reported by. ${ }^{8}$ The as-synthesized and the etched Pt-Ni products were dispersed in $15 \mathrm{~mL}$ of chloroform and incorporated onto carbon black (Vulcan XC-72) producing a metal loading of $20 \mathrm{wt} \%$ of Pt-Ni. The mixture was then sonicated for $5 \mathrm{~min}$. The loaded catalyst was then washed with hexane and collected by centrifugation at 3,500 RPM. The resultant Pt-Ni supported in carbon was dried in an oven for $14 \mathrm{~h}$ at a temperature of $180^{\circ} \mathrm{C}$.

\subsection{Characterization}

The samples that were loaded on Vulcan XC-72 and the unsupported samples were characterised using the following methods.

\subsubsection{Ashing}

Ashing was used to determine the platinum content loaded on the catalyst where a known mass of the Pt-Ni supported nanoparticles was measured and heated on the furnace at $700{ }^{\circ} \mathrm{C}$ for $2 \mathrm{~h}$ to burn carbon and nickel at a heating rate of $10^{\circ} \mathrm{C} / \mathrm{min}$. The metal loading was evaluated as:

$\%$ Ash $=\frac{M_{\text {ash }}}{M_{\text {dry }}} \times 100$

This will be compared to the Pt wt. \% that will be determined using inductively coupled plasma atomic emission spectroscopy (ICPOES).

\subsubsection{Transmission electron microscopy (TEM)}

TEM imaging was used to determine the formation of Pt-Ni nanostructures, the particle size of the catalyst, and particle size distribution. The analysis was performed at the University of Cape Town Imaging Centre.

\subsubsection{X-ray diffraction (XRD)}

$\mathrm{XRD}$ was used to determine the crystallographic structure of the material. The Bruker D8 Advance diffractometer fitted with a Co $\mathrm{K} \alpha$ source with a wavelength of $1.789 \AA$ was used to perform the $\mathrm{x}$-ray diffraction. The $2 \theta$ angular scan was measured from $10^{\circ}$ to $120^{\circ}$ using the Bruker XRD machine.

\subsubsection{Electrochemical analysis}

The ex-situ electrochemical characterization of the Pt-Ni supported on Vulcan XC-72 was determined using a thin-film rotating disc electrode (RDE). This was used to determine the Pt electrochemical surface area (ECSA) and its degradation after 7,200 cycles and 

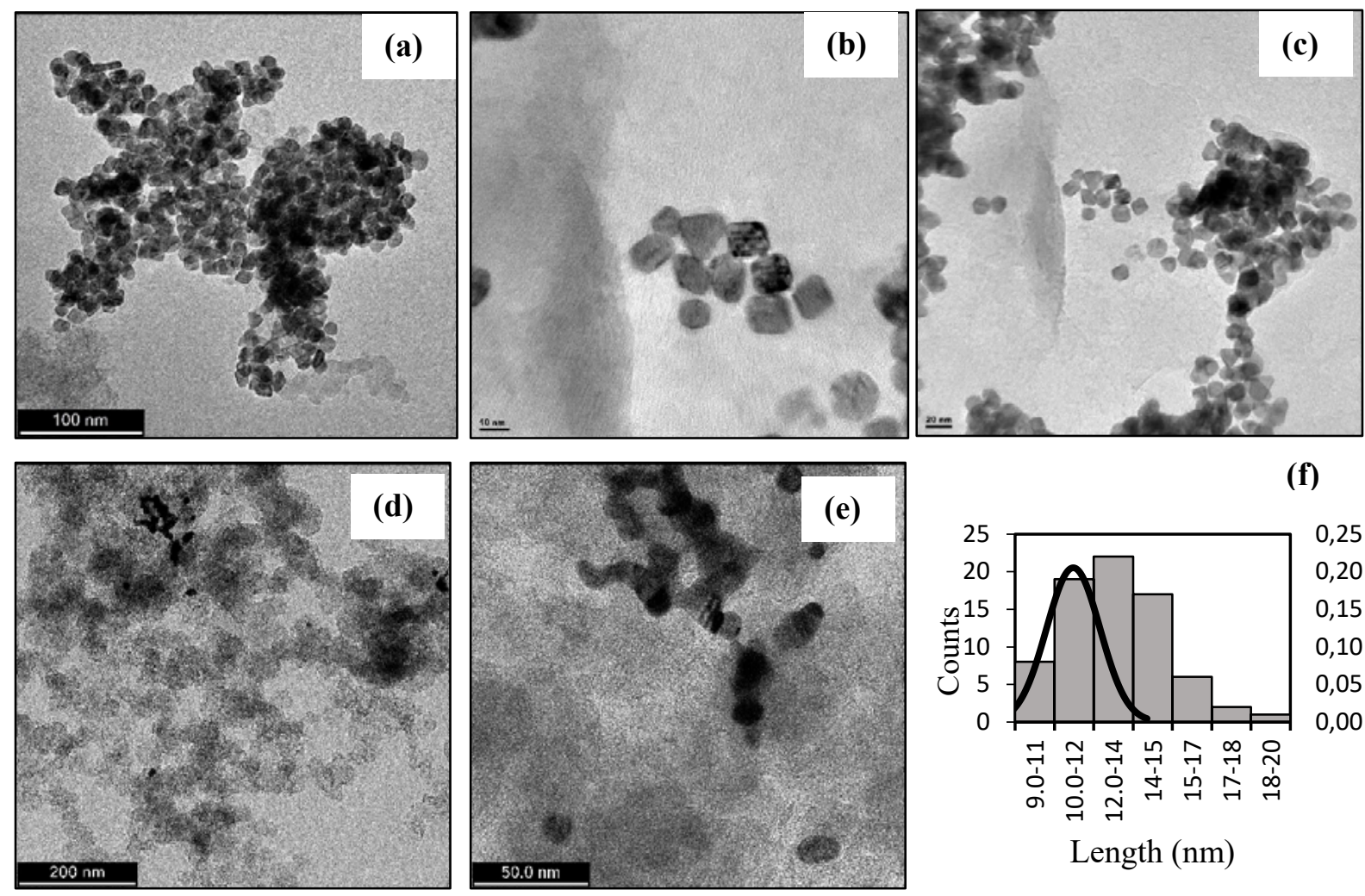

(f)

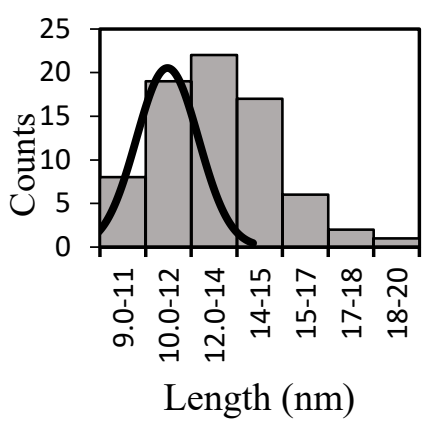

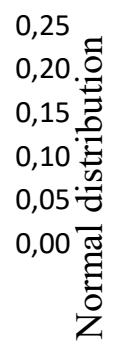

Figure 1: (a-c) TEM images of as-synthesized Pt-Ni at a resolution of (a)100 nm, (b) $10 \mathrm{~nm}$ and (c) $20 \mathrm{~nm}$, (d, e) TEM images of Pt-Ni supported in Vulcan XC-72 on a $50 \mathrm{~nm}$ and $200 \mathrm{~nm}$ scale, (f) Particle size distribution of Pt-Ni

the kinetic ORR activity. The catalyst layers were prepared by sonicating $10 \mathrm{mg}$ of catalyst in HPW for $30 \mathrm{~min} .10 \mu \mathrm{L}$ of the catalyst ink was then pipetted onto a clean $5 \mathrm{~mm}$ glassy carbon electrode to achieve a Pt loading of $28 \mu \mathrm{g}_{\mathrm{Pt}} / \mathrm{cm}_{\mathrm{GC}}{ }_{\mathrm{G}} .20 \mu \mathrm{L}$ of Nafion ${ }^{\mathrm{TM}}$ solution was added to the catalyst layer and dried for $10 \mathrm{~min}$ at $120^{\circ} \mathrm{C}$. The measurements were carried out using a three-electrode cell in $0.1 \mathrm{M} \mathrm{HClO}_{4}$ with saturated calomel electrode (SCE) as a reference electrode and a Pt strip as a counter electrode on an Auto lab PGSTAT302N potentionstat using NOVA v1.5 software. The Pt ECSA was determined by cyclic voltammetry in a glass cell at $25{ }^{\circ} \mathrm{C}$ in nitrogen-purged $0.1 \mathrm{M} \mathrm{HClO}_{4}$. Before measuring the 3 cycles at $20 \mathrm{mV} / \mathrm{s}$ to determine the hydrogen adsorption charge, the catalyst layers were conditioned for 15 cycles at $50 \mathrm{mV} / \mathrm{s}$ by cycling the potential between 0 and $1.2 \mathrm{~V}$ vs. RHE. The accelerated durability test (ADT) was determined under nitrogen-purged $0.1 \mathrm{M}$ $\mathrm{HClO}_{4}$ for 7,200 cycles. The ORR was also performed at $25^{\circ} \mathrm{C}$ in oxygen-purged $0.1 \mathrm{M} \mathrm{HClO}_{4}$ while rotating the electrode at 1,600 RPM.

\section{Results and discussion}

\subsection{Solvothermal synthesized Pt-Ni TEM analysis}

TEM images for as-synthesized Pt-Ni not supported on carbon at different resolutions; $100 \mathrm{~nm}, 10 \mathrm{~nm}$, and $20 \mathrm{~nm}$, respectively are shown in Figure 1 (a-c). The particles of Pt-Ni demonstrated defined polyhedra particles and no nanoframes were observed as seen in Figure $1(b, c)$. The TEM images of these Pt-Ni polyhedra deposited on Vulcan XC-72 showed little to no presence of PtNi nanoparticles and the Pt content was not spread entirely at the scale of $50 \mathrm{~nm}$ and $200 \mathrm{~nm}$, and small clusters were deposited on the surface as shown in Figure $1(\mathrm{~d}, \mathrm{e})$. It is suspected that the structure of Pt-Ni disintegrated during the loading process. Figure 1 (f) depicts a graph of the particle size distribution where the mean particle size of the Pt-Ni polyhedral particles was determined to be $13.34 \mathrm{~nm}$ after analysing 75 particles of Figure 1 (a).

\subsection{In-house developed and solvothermal Pt-Ni XRD analysis}

Figure 2 illustrates the XRD pattern for as-synthesized Pt-Ni/C, the etched samples $\mathrm{Pt}-\mathrm{Ni} / \mathrm{C} \mathrm{HOAc}$ and $\mathrm{Pt}-\mathrm{Ni} / \mathrm{C} \mathrm{HNO}_{3}$ that were prepared using the in-house developed method and $\mathrm{Pt}-\mathrm{Ni} / \mathrm{C}$ synthesized using the solvothermal method. Peak analysis revealed that the particle size for Pt-Ni/C as-synthesized, Pt-Ni/C HOAc, and $\mathrm{Pt}-\mathrm{Ni} / \mathrm{C} \mathrm{HNO}_{3}$ was $5.3 \mathrm{~nm}$ based on platinum peak p (220) in the literature, with the maximum peak height at $81^{\circ}$. The $2 \theta$ degree revealed platinum peaks at $29^{\circ}, 47^{\circ}$, and $81^{\circ}$ for all the catalysts with a slight shift to lower peaks when compared to literature. The patterns also show the presence of nickel at a $47^{\circ} 2 \theta$ degree peak. Based on peak p (220), the particle size for Pt-Ni solvothermal was determined to be $4 \mathrm{~nm}$. At a space group of Pm-3m (221), the crystalline structure was cubic with lattice parameters of 3.7500 for $\mathrm{a}=\mathrm{b}=\mathrm{c}$. Platinum was discovered to be present at the $47^{\circ}$ and $81^{\circ}$ peaks while nickel was discovered at a peak of $47^{\circ}$. The particle size of Pt in Pt-Ni from the solvothermal synthesis was larger in TEM when compared to XRD, with $13.34 \mathrm{~nm}$ and $4 \mathrm{~nm}$, respectively. This could be because the solvothermal Pt-Ni for XRD was supported on carbon and had undergone etching to remove the interior, resulting in smaller particle sizes, whereas the Pt-Ni for TEM was not supported on carbon or etched. This will 


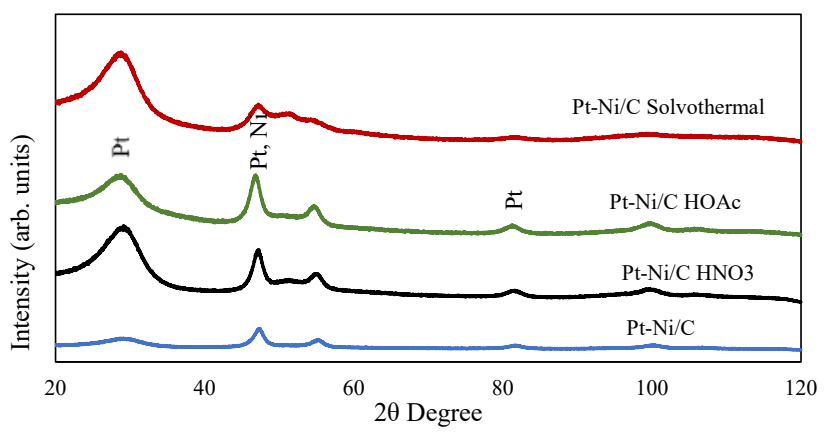

Figure 2: XRD pattern on $\mathrm{Pt}-\mathrm{Ni} / \mathrm{C}$ solvothermal, as-synthesized $\mathrm{Pt}-\mathrm{Ni} / \mathrm{C}$, the etched samples Pt-Ni/C HOAc and Pt-Ni/C $\mathrm{HNO}_{3}$

be confirmed further with TEM was not supported on carbon or etched. This will be confirmed further with TEM.

\subsection{The ex-situ performance analysis}

The mass and specific activity of commercial HySA K40 Pt/C are shown in Figure 3 (a), as well as the in-house developed $\mathrm{Pt}-\mathrm{Ni} / \mathrm{C}$ as-synthesized, etched $\mathrm{Pt}-\mathrm{Ni} / \mathrm{C} \mathrm{HOAc}$ and $\mathrm{Pt}-\mathrm{Ni} / \mathrm{C} \mathrm{HNO}_{3}$ and $\mathrm{Pt}-\mathrm{Ni} / \mathrm{C}$ synthesized with the solvothermal method. ORR mass activity and specific activity were determined using thin-film RDE measurements at $900 \mathrm{mV}$ versus RHE. Pt-Ni/C as-synthesized showed a high specific activity of $358 \mu \mathrm{A} / \mathrm{cm}^{2}{ }_{\mathrm{Pt}}$ compared to Pt$\mathrm{Ni} / \mathrm{C} \mathrm{HOAc}, \mathrm{Pt}-\mathrm{Ni} / \mathrm{C} \mathrm{HNO}_{3}$, and Pt-Ni/C solvothermal reading 51, 160 , and $122 \mu \mathrm{A} / \mathrm{cm}_{\mathrm{Pt}}^{2}$, respectively. The $\mathrm{Pt}-\mathrm{Ni} / \mathrm{C}$ as-synthesized also showed 2 times enhancement on specific activity when compared to the commercial HySA K40 Pt/C with $182 \mu \mathrm{A} / \mathrm{cm}^{2}{ }_{\mathrm{Pt}}$, but the mass activity of the commercial HySA K40 Pt/C was higher compared to other catalysts with a mass activity reading of $194 \mathrm{~mA} / \mathrm{mg}_{\mathrm{Pt}}$. The Pt-Ni/C, Pt-Ni/C HOAc, Pt-Ni/C $\mathrm{HNO}_{3}$, and Pt$\mathrm{Ni} / \mathrm{C}$ solvothermal measured $183,33,11$, and $43 \mathrm{~mA} / \mathrm{mg}_{\mathrm{Pt}}$ of mass activities, respectively. in Figure 3 (b) shows the ORR polarization curves measured in oxygen saturated $0.1 \mathrm{M} \mathrm{HClO}_{4}$ electrolyte solutions. The $\mathrm{Pt}-\mathrm{Ni} / \mathrm{C}$ as-synthesized electrocatalyst prepared using the in-house developed method resulted in better-performing catalysts with low current density and potential when compared to the Pt-Ni/C HOAc, Pt-Ni/C $\mathrm{HNO}_{3}$ and $\mathrm{Pt}-\mathrm{Ni} / \mathrm{C}$ solvothermal. These findings suggest that when operating at low current density, the cell voltage rises, providing more electrochemical energy for degradation mechanisms and that the cell design can be optimized for high-power conditions.

Figure $4(\mathrm{a}, \mathrm{b})$ shows the ECSA and cyclic voltammogram $(\mathrm{CV})$ results of $\mathrm{Pt}-\mathrm{Ni} / \mathrm{C}$ as-synthesized, etched $\mathrm{Pt}-\mathrm{Ni} / \mathrm{C} \mathrm{HOAc}$ and $\mathrm{Pt}-$ $\mathrm{Ni} / \mathrm{C} \mathrm{HNO}_{3}$ supported on Vulcan XC-72 prepared using the inhouse developed method compared to the commercial HySA K40 Pt/C. The ECSA of Pt-Ni/C, Pt-Ni/C HOAc, Pt-Ni/C $\mathrm{HNO}_{3}$, and commercial HySA K40 Pt/C were 51, 66, 35 and $106 \mathrm{~m}^{2 /}$ $\mathrm{g}_{\mathrm{pt}}$ respectively. The $\mathrm{CV}$ results obtained during electrochemical activation show that the commercial catalyst has a larger surface area as shown in Figure 4 (b) compared to the acid-etched samples and the as-synthesized. Figure 4 (c) shows the stability results after 7,200 cycles of accelerated durability testing (ADT). The Pt-Ni/C as-synthesized gained approximately $24.6 \%$ ECSA compared to etched Pt-Ni/C HOAc, Pt-Ni/C $\mathrm{HNO}_{3}$ and commercial HySA K40 $\mathrm{Pt} / \mathrm{C}$ which lost 34, 43, and $33 \%$ ECSA respectively. According to the ADT results from the literature studies ${ }^{8}$ the catalyst prepared by nitrification had an ECSA loss of $14 \%$ compared to the in-house developed catalyst, which had a loss of $43 \%$. The as-synthesized catalyst was discovered to be the better performing catalyst in terms of ECSA percent of hydrogen adsorption charge decay undergoing electrochemical corrosion in the presence of $0.1 \mathrm{M} \mathrm{HClO}_{4}$.

\section{Conclusion}

The Pt-Ni nanoframes were synthesized using two methods and the resulting as-synthesized, etched, and unsupported catalysts were compared. The method to produce Pt-Ni alloy using the in-house developed method was more efficient compared to the solvothermal method considering the reaction time, energy input, and chemical reagents required. The analysis of these catalysts via XRD and TEM showed Pt-Ni structures. However, evolution into Pt-Ni nanoframes is still yet to be determined. The ex-situ performance results show that the as-synthesized Pt-Ni electrocatalyst prepared using an in-house developed method outperformed other catalysts in terms of ORR mass activity. Further investigation of nanoframes is required to determine the formation of nanoframes from polyhedral structures as well as the elemental characterization of the frames.

(a)
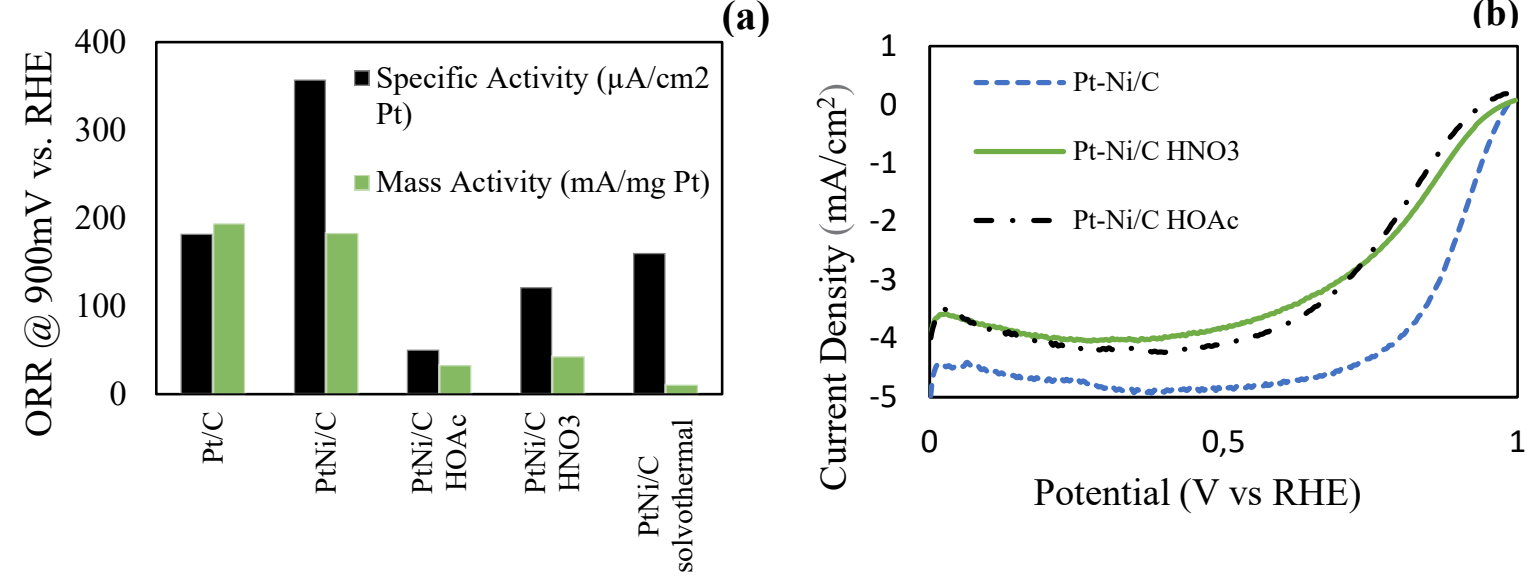

Figure 3: (a) Mass and specific activity at $900 \mathrm{mV}$ (vs. RHE) and (b) oxygen reduction reaction (ORR) polarization curves. 

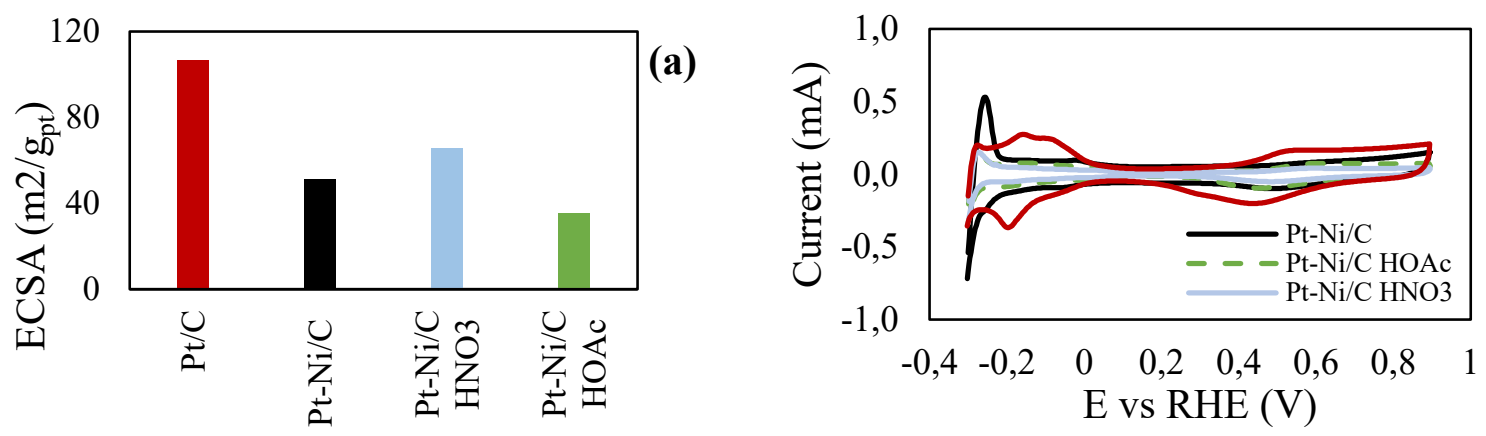

(b)

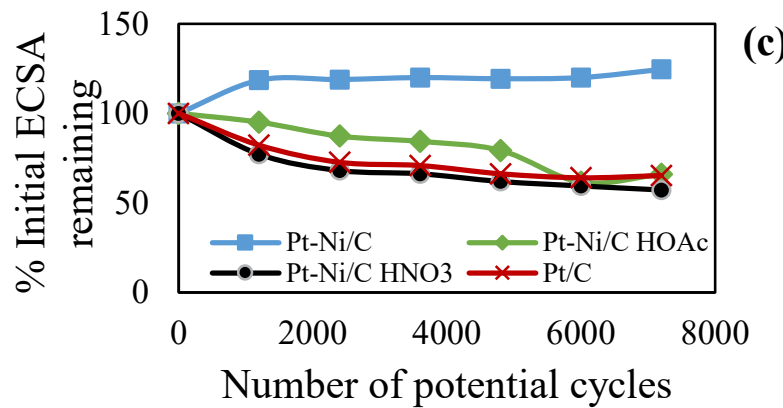

(c)

Figure 4: (a) electrochemical surface area, (b) cyclic voltammogram and (c) accelerated durability test for commercial HySA K40 Pt/C, $\mathrm{Pt}-\mathrm{Ni} / \mathrm{C}$, etched $\mathrm{Pt}-\mathrm{Ni} / \mathrm{C} \mathrm{HOAc}$, and $\mathrm{Pt}-\mathrm{Ni} / \mathrm{C} \mathrm{HNO}_{3}$ catalyst

\section{Acknowledgments}

The authors are grateful to the Mineral Science Council of South Africa (Mintek) and HySA Catalysis under catalysis on Project No. ADE32101 for financial support.

\section{References}

1. Ruano P, Delgado LL, Picco S, Villegas L, Tonelli F, Merlo $\mathrm{M}$, et al. We are IntechOpen, the world's leading publisher of Open Access books Built by scientists, for scientists TOP $1 \%$. Intech [Internet]. 2016;(tourism):13. Available from: https:// www.intechopen.com/books/advanced-biometric-technologies/ liveness-detection-in-biometrics

2. Ren X, Lv Q, Liu L, Liu B, Wang Y, Liu A, et al. Current progress of Pt and Pt-based electrocatalysts used for fuel cells. Sustain Energy Fuels. 2019;4(1):15-30.

3. Ganesan A, Narayanasamy M. Ultra-low loading of platinum in proton exchange membrane-based fuel cells: a brief review. Mater Renew Sustain Energy [Internet]. 2019;8(4):1-14. Available from: https://doi. org/10.1007/s40243-019-0156-X

4. Xie C, Niu Z, Kim D, Li M, Yang P. Surface and Interface Control in Nanoparticle Catalysis. Chem Rev. 2020;120(2):1184-249.
5. Popov BNBBNB, Weidner J. VD 13 Development of Ultra-Low Platinum Alloy Cathode Catalysts for PEM Fuel Cells. HydrogendoedevNrelGov [Internet]. 2016;(303):764-9. Available from: http://hydrogendoedev.nrel.gov/pdfs/progress12/v_d_13 popov_2012.pdf\%0Ahttp://www.osti.gov/servlets/purl/1330985

6. Nosheen F, Anwar T, Siddique A, Hussain N. Noble metal-based alloy nanoframes: Syntheses and applications in fuel cells. Front Chem. 2019;7(JUL).

7. Jaouen F, Jones D, Coutard N, Artero V, Strasser P, Kucernak A. Toward platinum group metal-free catalysts for hydrogen/air protonexchange membrane fuel cells. Johnson Matthey Technol Rev. 2018;62(2):231-55.

8. Chen S, Niu Z, Xie C, Gao M, Lai M, Li M, et al. Effects of catalyst processing on the activity and stability of Pt-Ni nanoframe electrocatalysts. ACS Nano. 2018;12(8):8697-705.

9. Chen C, Kang Y, Huo Z, Zhu Z, Huang W, Xin HL, et al. Highly crystalline multimetallic nanoframes with three-dimensional electrocatalytic surfaces. Science (80- ). 2014;343(6177):1339-43.

10. Becknell N, Son Y, Kim D, Li D, Yu Y, Niu Z, et al. Control of Architecture in Rhombic Dodecahedral Pt-Ni Nanoframe Electrocatalysts. J Am Chem Soc. 2017;139(34):11678-81.

11. Peng X, Zhao S, Omasta TJ, Roller JM, Mustain WE. Activity and durability of Pt-Ni nanocage electrocatalysts in proton exchange membrane fuel cells. Appl Catal B Environ [Internet]. 2017;203:92735. Available from: http://dx.doi.org/10.1016/j.apcatb.2016.10.081 